\title{
An arabinoxylan-rich fraction from wheat enhances caecal fermentation and protects colonocyte DNA against diet-induced damage in pigs
}

\author{
Damien P. Belobrajdic ${ }^{1,2}$, Anthony R. Bird ${ }^{1,2}$, Michael A. Conlon ${ }^{1,2}$, Barbara A. Williams ${ }^{1,3}$, \\ Seungha Kang ${ }^{4}$, Christopher S. McSweeney ${ }^{4}$, Dagong Zhang ${ }^{1,3,5}$, Wayne L. Bryden ${ }^{1,3,5}$, \\ Michael J. Gidley ${ }^{1,3}$ and David L. Topping ${ }^{1,2 *}$ \\ ${ }^{1}$ High Fibre Grains Cluster, CSIRO Food Futures National Research Flagship, Adelaide, SA 5000, Australia \\ ${ }^{2}$ CSIRO Food Futures National Research Flagship, PO Box 10041, Adelaide, SA 5000, Australia \\ ${ }^{3}$ Centre for Nutrition and Food Sciences, University of Queensland, St Lucia, QLD 4072, Australia \\ ${ }^{4}$ CSIRO Livestock Industries, St Lucia, QLD 4067, Australia \\ ${ }^{5}$ School of Agriculture and Food Sciences, University of Queensland, Gatton, QLD 4343, Australia
}

(Submitted 27 January 2011 - Final revision received 1 July 2011 - Accepted 6 July 2011 - First published online 24 November 2011)

\begin{abstract}
Population studies show that greater red and processed meat consumption increases colorectal cancer risk, whereas dietary fibre is protective. In rats, resistant starches (a dietary fibre component) oppose colonocyte DNA strand breaks induced by high red meat diets, consistent with epidemiological data. Protection appears to be through SCFA, particularly butyrate, produced by large bowel carbohydrate fermentation. Arabinoxylans are important wheat fibre components and stimulate large bowel carbohydrate SCFA production. The present study aimed to determine whether an arabinoxylan-rich fraction (AXRF) from wheat protected colonocytes from DNA damage and changed colonic microbial composition in pigs fed with a diet high (30\%) in cooked red meat for 4 weeks. AXRF was primarily fermented in the caecum, as indicated by higher tissue and digesta weights and higher caecal (but not colonic) acetate, propionate and total SCFA concentrations. Protein fermentation product concentrations (caecal $p$-cresol and mid- and distal colonic phenol) were lower in pigs fed with AXRF. Colonocyte DNA damage was lower in pigs fed with AXRF. The microbial profiles of mid-colonic mucosa and adjacent digesta showed that bacteria affiliating with Prevotella spp. and Clostridial cluster IV were more abundant in both the mucosa and digesta fractions of pigs fed with AXRF. These data suggest that, although AXRF was primarily fermented in the caecum, DNA damage was reduced in the large bowel, occurring in conjunction with lower phenol concentrations and altered microbial populations. Further studies to determine the relationships between these changes and the lowering of colonocyte DNA damage are warranted.
\end{abstract}

\section{Key words: Wheat arabinoxylan: DNA damage: SCFA: Colorectal cancer}

Morbidity and mortality due to non-infectious large bowel diseases including colorectal cancer (CRC) are major problems for people living in developed economies ${ }^{(1)}$. These diseases are also emerging as serious issues in developing countries in which traditional diets are changing as a result of greater affluence $^{(2)}$. Diet and lifestyle are important risk factors for these conditions, and prevention is the preferred strategy. Large prospective cohort studies have identified a number of modifiable risk factors for CRC, and the consumption of red and processed meats has been shown to increase the risk ${ }^{(3)}$. Other prospective studies have shown that greater whole grain food consumption lowers the risk of a number of dietrelated conditions relative to refined diets ${ }^{(4-6)}$. These findings are consistent with early observational studies that identified whole grain consumption as a contributor to the low incidence of constipation, diverticular disease, CRC and other non-infectious illnesses in indigenous populations consuming traditional diets ${ }^{(7)}$. The high intake of plant foods by groups such as native (black) Africans relative to Europeans who ate refined foods led to the identification of dietary fibre as a key protective factor.

The resistance of NSP to human and animal small intestinal enzyme digestion helps to explain the beneficial effects of insoluble fibre on laxation through greater faecal bulking ${ }^{(8)}$. However, the relationship between dietary fibre consumption and CRC is less clear. Some population studies ${ }^{(9)}$ have shown a strong protective effect, but others ${ }^{(10)}$ have not. Some of the uncertainty may reside in the lack of appreciation of the

Abbreviations: AXRF, arabinoxylan-rich fraction; CRC, colorectal cancer; cRNA, complementary RNA

*Corresponding author: Dr D. L. Topping, fax +61 88303 8899, email david.topping@csiro.au 
importance of other indigestible polysaccharides in the original observational studies that led to the development of the 'fibre hypothesis'. For example, it has transpired that the staple maize porridge of the black African population is comparatively low in dietary fibre ${ }^{(11)}$, but contains a relatively high level of resistant $\operatorname{starch}^{(12)}$. Resistant starch contributes to total fibre intake and appears to promote large bowel health through SCFA generated by colonic bacterial fermentation ${ }^{(13)}$.

Experimental studies have shown that one acid in particular, butyrate, is effective in promoting colonic function and maintaining a normal colonocyte phenotype ${ }^{(14)}$. Although a direct role of butyrate in preventing CRC is yet to be determined, the circumstantial evidence is strong. Butyrate promotes apoptosis in CRC cell lines in vitro. Elevation of large bowel total SCFA ${ }^{(14)}$, including butyrate, opposes the formation of tumours in rodents treated with azoxymethane ${ }^{(15)}$. In addition, feeding of resistant starch opposes colonic DNA damage induced by dietary protein (including red meat) in rats ${ }^{(16,17)}$, consistent with the population data that links meat and dietary protein intakes $^{(3,6,18,19)}$ to CRC risk.

Although an extensive body of data describes the effects of major fibre components on colonic health in humans and animal models ${ }^{(20)}$, arabinoxylans have received relatively little attention. These pentosans are especially high in wheat, and there are data supporting their important contribution to the laxative action of wheat fibre ${ }^{(8)}$. There is also evidence that these NSP can promote SCFA production in rats ${ }^{(21)}$, but reports of their effects on other bowel health indices are scarce. There are also relatively few data on the relationship between arabinoxylans and the large bowel microbiota, especially in pigs. This species is considered to be a good model for human nutritional studies, especially those examining diet and large bowel function ${ }^{(13)}$. The aim of the present pilot study was to examine the effects of an arabinoxylanrich fraction (AXRF) from wheat on large intestinal fermentation characteristics and colonocyte DNA damage in pigs fed with a diet high in cooked red meat.

\section{Materials and methods}

\section{Animals and housing}

A total of ten 9-week-old male pigs of a commercial Large White strain were obtained from the University of Queensland piggery. The pigs had an average starting weight of $27 \mathrm{~kg}$ and were housed in individual pens in a temperature-controlled room $\left(22 \pm 2^{\circ} \mathrm{C}\right)$ at the Centre for Advanced Animal Science (University of Queensland, Gatton, QLD, Australia). The pigs had a $14 \mathrm{~d}$ adaption period, wherein they were gradually introduced to their experimental diet. Before the commencement of the experimental period, the pigs were matched by weight and randomly allocated to one of the two experimental diets. Experimental procedures involving pigs were approved by the Animal Ethics Committees of the University of Queensland and CSIRO Food and Nutritional Sciences.

\section{Arabinoxylan-rich fraction}

The AXRF was obtained as a liquid from a flour-milling company (Penfords, Tamworth, NSW, Australia) and after drying (Nutradry, Brisbane, QLD, Australia), it comprised approximately $226 \mathrm{~g} / \mathrm{kg}$ arabinoxylan, $550 \mathrm{~g} / \mathrm{kg}$ starch and $324 \mathrm{~g} / \mathrm{kg}$ other components, mainly lignocellulosic material, protein and minerals.

\section{Diets and feeding procedures}

Pigs were fed with a high-protein diet comprising of commercially available human food ingredients, which met their macronutrient requirements at a daily intake of $70 \mathrm{~g} / \mathrm{kg}^{0.75}$ body weight. The composition of the two diets is shown in Table 1 . The diet allocation was increased weekly, in keeping with body weight gain. The pigs received two meals per $\mathrm{d}$ (morning and afternoon) and had free access to water. Following adaptation, the animals were fed with the experimental diets for 4 weeks.

The experimental diets included the two dietary treatments (with and without added AXRF) and contained $300 \mathrm{~g} / \mathrm{kg}$ red meat (round rump boneless beef steak, trimmed of fat) that had been cooked on a hotplate until lightly browned. The meat contained $330 \mathrm{~g} / \mathrm{kg}$ protein, $96 \mathrm{~g} / \mathrm{kg}$ fat and $570 \mathrm{~g} / \mathrm{kg}$ moisture, was minced and then frozen at $-20^{\circ} \mathrm{C}$ in vacuumsealed plastic bags. The AXRF supplemented diet contained $370 \mathrm{~g} / \mathrm{kg}$ AXRF, providing $129 \mathrm{~g}$ of arabinoxylan per $\mathrm{kg}$ diet and this was balanced by the addition of extra starch to the control diet. Wheat bran was added to both diets $(40 \mathrm{~g} / \mathrm{kg})$ to maintain laxation. Vitamins and minerals were provided by the addition of a Premax Pig Premixe (CCD Animal Health and Nutrition, Toowoomba, QLD, Australia; Table 1).

\section{Sampling protocol}

After maintaining for 4 weeks on diet, pigs were anaesthetised using isoflourane (Delvet, Seven Hills, NSW, Australia) and the large intestine was tied off into sections before being removed from the animal, which was then euthanised before

Table 1. Composition of experimental diets*

\begin{tabular}{lcc}
\hline & Control diet & AXRF diet \\
\hline Cooked red meat† & 300 & 300 \\
AXRF $\ddagger$ & 0 & 370 \\
Wheat bran & 40 & 40 \\
Starch & 535 & 165 \\
Sucrose & 70 & 70 \\
Sunflower oil & 50 & 50 \\
NaCl & 3 & 3 \\
Vitamin and mineral mix§ & 2 & 2 \\
\hline
\end{tabular}

AXRF, arabinoxylan-rich fraction.

* Given as dry weight in $\mathrm{g} / \mathrm{kg}$.

† Red meat quantity is reported as amount added as dry equivalents. Actua composition (wet weight): $33 \%$ protein, $9.6 \%$ fat, $43 \% \mathrm{DM}$ and $57 \%$ moisture.

‡ AXRF composition: $22.6 \%$ arabinoxylan, $55 \%$ starch and $32.4 \%$ other components. AXRF did not contain any resistant starch.

$\S$ Vitamin and mineral mix provided $2.8 \mathrm{mg}$ vitamin $\mathrm{A}, 0.0675 \mathrm{mg}$ vitamin $\mathrm{D}, 26.7 \mathrm{~g}$ vitamin $E, 4 \mathrm{~g}$ riboflavin $B_{2}, 1.3 \mathrm{~g}$ pyridoxine $B_{6}, 13.3 \mathrm{mg}$ cyanocobalamin $B_{12}$ $1.3 \mathrm{~g}$ menadione $\mathrm{K}, 10.7 \mathrm{~g}$ calcium pantothenate, $133 \mathrm{~g} \mathrm{Zn}, 26.7 \mathrm{~g} \mathrm{Cu}, 107 \mathrm{~g} \mathrm{Fe}$ $53 \mathrm{~g} \mathrm{Mn}, 0.3 \mathrm{~g} \mathrm{Co}, 1 \mathrm{~g}$ iodine, $0.13 \mathrm{~g}$ Se per $\mathrm{kg}$ of diet. 
it regained consciousness. After removal from the body, the caecum and the remainder of the large intestine were subdivided into approximately equal parts: the proximal, middle and distal sections. The digesta was collected from all four sections and stored frozen $\left(-20^{\circ} \mathrm{C}\right)$.

A $6 \mathrm{~cm}^{2}$ segment of colon tissue was removed from the proximal, mid- and distal colon immediately following autopsy. Each segment was placed in Hank's buffered saline solution and colonocytes were isolated following a method previously described ${ }^{(22)}$ with modifications. In brief, the tissue was incubated with $6 \mathrm{mg} / \mathrm{ml}$ dithiothreitol in a $50 \mathrm{ml}$ tube at $37^{\circ} \mathrm{C}$ for $10 \mathrm{~min}$ with shaking. The tissue was then washed with Hank's buffered saline solution and then digested with $1.2 \mathrm{mg} / \mathrm{ml}$ proteinase $\mathrm{K}$ at $37^{\circ} \mathrm{C}$ for $20 \mathrm{~min}$ with continuous shaking. The digestion solution was collected, combined with Dulbecco's modified Eagle's medium used to wash the colon tissue, and centrifuged at $1500 \mathrm{~g}$ for $8 \mathrm{~min}$. The cell pellet was then resuspended in fresh Dulbecco's modified Eagle's medium for use in the Comet assay.

\section{Analyses}

SCFA, phenol, cresol, ammonia, DM. Caecal and colonic digesta contents were thawed and then distilled and homogenised with $20 \mu \mathrm{l}$ of $1.68 \mathrm{~mm}$ of internal standard (heptanoic acid). The contents were analysed for all major and minor SCFA, in duplicate, using an Agilent Technologies $6890 \mathrm{~N}$ Network Gas Chromatograph System fitted with a Zebron ZB-FFAP column $(0.53 \mathrm{~mm}, 30 \mathrm{~m}$; Phenomenex, Torrance, CA, USA), as described previously ${ }^{(23)}$. SCFA are expressed as concentration $(\mu \mathrm{mol} / \mathrm{g})$. Caecal SCFA were also expressed as pools to represent the total amount of SCFA available. The following formula was used: SCFA concentration $(\mathrm{mm} / \mathrm{g})$ $\times$ total caecum digesta weight $(\mathrm{g})$.

Phenols and cresols were determined by adding three times the sample weight of internal standard solution $(100 \mathrm{mg} / \mathrm{ml}$ of 2-methylphenol) to the sample and mixing thoroughly on a vortex mixer. The mixtures were centrifuged $(2000 \mathrm{~g}$, $15 \mathrm{~min}$ at $4^{\circ} \mathrm{C}$ ) and the supernatants were distilled as described elsewhere $^{(24)}$. The distillates were analysed on a Shimadzu HPLC system comprising an LC10-AT pump, Sil-10A injector and a RF-10AXL fluorescence detector (ex $284 \mathrm{~nm}$, em $310 \mathrm{~nm}$; Shimadzu, Kyoto, Japan). Samples $(30 \mathrm{ml})$ were separated on Varian Microsorb $5 \mathrm{~mm}$ C18 column $(250 \mathrm{~mm} \times 4.6 \mathrm{~mm}$; Varian, Lake Forest, CA, USA), which was eluted at $1 \mathrm{ml} / \mathrm{min}$ with 70:30 water-acetonitrile mixture adjusted to $\mathrm{pH} 3 \cdot 2$ with acetic acid.

Ammonia was analysed using a method modified from Baethgen \& Alley ${ }^{(25)}$. In brief, ammonium nitrogen was determined colorimetrically, using the chemical reaction of ammonium ions $\left(\mathrm{NH}_{4}^{+}\right)$with sodium salicylate and nitroprusside in a weakly alkaline buffer, at a wavelength of $650 \mathrm{~nm}$ using a UV/visible spectrophotometer (Automated Discrete Analyzer Model AQ2+; SEAL Analytical Limited, Fareham, UK).

Comet assay. The single-cell gel electrophoresis (Comet) assay was used to measure DNA single-strand breaks in colonocytes isolated from the proximal, mid- and distal colon of each pig, as described previously ${ }^{(26,27)}$. Fluorescent images were obtained by propidium iodide staining and image capture using an Olympus microscope (BX41; Olympus, Tokyo, Japan) and digital Spot camera (RT Color; Diagnostic Instruments, Sterling Heights, MI, USA). Image analysis was conducted using Scion Image Beta 4.02 (Scion Corporation, Frederick, MD, USA) and a public domain macro ${ }^{(28)}$. The Comet tail moment was calculated for each cell by multiplying the tail length by the fraction of DNA in the tail. This was calculated for fifty cells per slide in triplicate for each colonic segment.

Bacterial profile of mucosa and digesta from mid-colon. A custom phylogenetic microarray developed and validated for gut bacteria was used to analyse the microbiota ${ }^{(29)}$. A $6 \mathrm{~cm}^{2}$ section of mid-colon tissue was rinsed thoroughly in PBS to remove digesta material, the mucosa was scraped using a microscope slide and placed in RNAlater buffer solution (Qiagen Inc., Valencia, CA, USA). Digesta adjacent to the colon tissue was collected and stored in RNAlater buffer. The samples were stored in liquid $\mathrm{N}_{2}$ until DNA extraction was conducted. All DNA were extracted by repeated bead beating and a column cleanup method ${ }^{(30)}$. Prokaryote $16 \mathrm{~S}$ rRNA genes were amplified using the primer sets $27 \mathrm{~F}$ ( $5^{\prime}$-AGAGTTTGATCMTGGCTCAG-3') and T7/1492R (5'-TCTAATACGACTCACTATAGGGGGYTACCTTGTTACGACTT- $3^{\prime}$; the italicised region is modified to include a $\mathrm{T} 7$ promoter sequence $)^{(31)}$. The PCR amplicons were purified with the MinElute PCR purification kit (Qiagen Inc.) and then added as a template for in vitro transcription-based synthesis of single-stranded RNA (complementary RNA, cRNA) using the MEGAScript $\mathrm{T} 7$ In vitro transcription kit (Ambion, Austin, TX, USA). After purification with a MEGAclear Kit (Ambion), $1 \mu \mathrm{g}$ of the sample cRNA and $140 \mathrm{ng}$ of standard cRNA were labelled at the same time using Label IT MicroArray Cy5 reagent (Mirus, Madison, WI, USA) for $1 \mathrm{~h}$ at $37^{\circ} \mathrm{C}$ while being protected from light, and then $0 \cdot 1$ volumes of the $10 \times$ stop reagent were added (Mirus) to terminate the labelling reaction. The labelled cRNA $(25 \mu \mathrm{l})$ was fragmented using $5 \times$ fragmentation buffer (Mirus) at $94^{\circ} \mathrm{C}$ for $15 \mathrm{~min}$ so that the effects of fragmentation on signal intensity could be evaluated on the microarray. Without further purification steps that compromised signal intensity, $6 \mu \mathrm{l}$ (approximately $120 \mathrm{ng}$ ) of the labelled cRNA samples in $24 \mu$ l hybridisation solution were hybridised with the microarray (CombiMatrix, Mukilteo, WA, USA) at $42^{\circ} \mathrm{C}$ overnight, as described by Kang et al. ${ }^{(29)}$.

Colonic mucus layer thickness. A $4 \mathrm{~cm}^{2}$ segment of colon was removed from the proximal, mid- and distal colon of each pig and the mucosal surface was washed gently with $0 \cdot 15 \mathrm{M}-$ $\mathrm{NaCl}$ solution to remove the digesta. The thickness of mucus lining the colon was determined by further cutting the tissue into 1.6-mm length pieces and then placed into a clear plastic viewing chamber. To view and capture images of the mucus thickness, the viewing chamber was placed on to a dissecting microscope (Nikon C-LEDS; Nikon, Shanghai, China), the tissue being illuminated from above and below, and images of the mucus layer were captured using a digital camera (Moticam 2000; Motic China Group, Xiamen, China). The mucus thickness was measured using image analysis software 
(Motic Images Plus 2.0; Motic China Group). For each animal, ten measurements were taken at different points along four tissue segments to give forty thickness measurements in total.

\section{Statistical analyses}

Data for cresol, phenol and cell characteristics are presented as the mean values and standard errors of the mean for each treatment group. Repeated-measures ANOVA was used to identify whether diet treatment affected the digesta composition or DNA damage measures in the different sites of the colon. A two-tailed Student's $t$ test was used to identify whether AXRF had any effects at individual sites of the colon. Statistical analysis was performed using SPSS for Windows 17.0 software (SPSS Inc., Chicago, IL, USA), with statistical significance set at a level of $P<0.05$.

\section{Results}

\section{Feed consumption and body weight gain}

The mean live weight at the start of the experiment was $27 \cdot 3$ (sE 0.6) kg ( $n$ 10; both groups combined). All feed was consumed promptly on presentation. There was no effect of diet on live weight gain, and the mean body weight at the end of the experiment was $52 \cdot 1$ (SE 1.2) kg ( $n$ 10; both groups combined). There was no significant difference in liver weights due to diet (data not shown).

\section{Large intestine measures}

Tissue weight and length. The caecum tissue (AXRF 221 (SE 29) and control 112 (sE 27) g, $P<0.001$ ) and content weights (AXRF 195 (SE 27) and control 80 (sE 24) g, $P<0.05$ ) were higher for pigs fed with the AXRF diet. The AXRF diet had no effect on the length of the small intestine (AXRF diet 12.9 (SE 0.7) and control diet $12.1(\mathrm{SE} 0.7) \mathrm{m}$ ) or large intestine (AXRF diet 2.9 (SE 0.02) and control diet 2.4 (SE 0.02) m), compared with the control diet. For all sections of the large intestine, the amount of DM was significantly higher for pigs fed with the AXRF diet (Table 2).

Digesta SCFA. The AXRF-fed animals had increased acetate $(P<0.01)$, propionate $(P<0.01)$ and total SCFA $(P<0.05)$ concentrations in the caecal digesta (Table 2). The AXRF-fed animals had increased acetate (control 6.2 (SE 2.8) and AXRF 21.7 (se 3.1) mM, $P<0.01$ ), propionate (control 2.6 (sE 1.6) and AXRF 12.4 (SE 1.8) mm, $P<0.01$ ) and total SCFA (control 10.1 (se 5.0) and AXRF 37.5 (se 5.5) mm, $P<0.01$ ) pools in the caecal digesta.

Concentrations of total SCFA and of acetate and propionate were significantly higher in caecal digesta of pigs fed with AXRF, but not at any colonic sampling site (Table 2). The AXRF-fed animals had increased acetate (control 6.2 (SE 2.8) and AXRF $21.7(\mathrm{se} \mathrm{3.1)} \mathrm{mm}, P<0 \cdot 01$ ), propionate (control 2.6 (SE 1.6) and AXRF 12.4 (SE 1.8) mM, $P<0.01$ ) and total SCFA (control 10.1 (sE 5.0) and AXRF 37.5 (SE 5.5) mm, $P<0.01$ ) pools in the caecal digesta. Butyrate concentrations in the digesta from all sites of the large intestine were unaffected by AXRF (Table 2), whereas caecal digesta butyrate pools

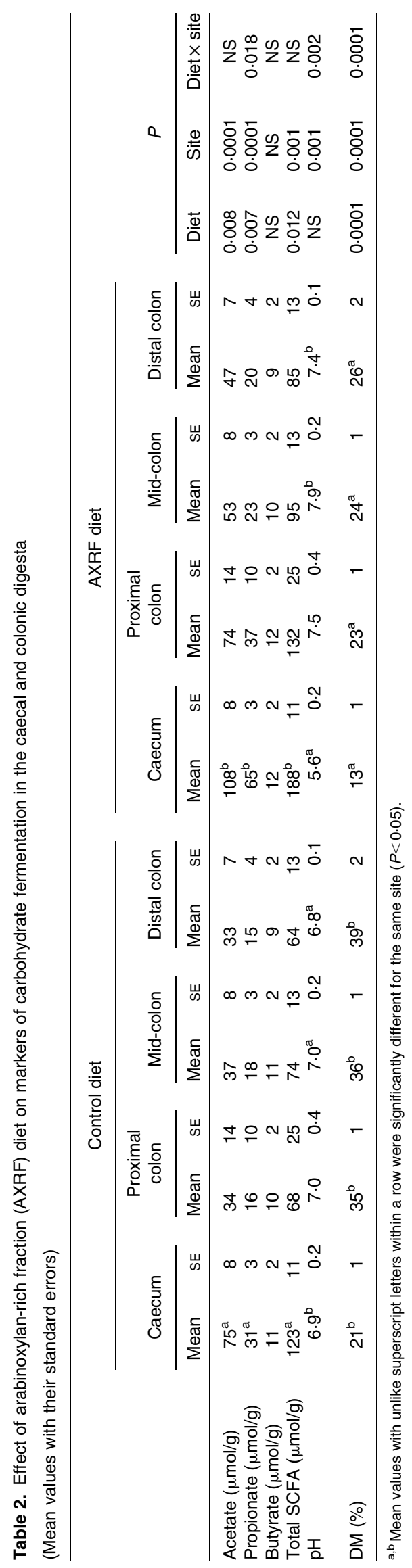


were unaffected by diet (control 0.9 (SE 0.5 ) and AXRF 2.6 (SE 0.6) $\mathrm{mm}, P=0.075$ ).

$\mathrm{pH}$. The $\mathrm{pH}$ of the digesta in the control group was similar between the sites of the large bowel (Table 2). In comparison to the control diet, the AXRF diet lowered the $\mathrm{pH}$ of the caecal digesta $(P<0.01)$ and raised the $\mathrm{pH}$ of the digesta in the midand distal colon $(P<0.01$; Table 2$)$. In the caecum, the $\mathrm{pH}$ of the digesta inversely correlated with acetate $(r-0.783$, $P<0.01)$, propionate $(r-0.908, P<0.0001)$ and total SCFA $(r-0.853, P<0.01)$ concentrations.

DNA damage. The AXRF diet lowered colonocyte DNA damage $(P<0.05$; Fig. 1$)$ overall, when assessed for all three colon sites. There was a trend to a reduction in tail moment primarily in the distal colon (control diet 36 (SE 9) and AXRF diet 21 (sE 4), $P=0 \cdot 15$; Fig. 1 ).

Protein fermentation. In comparison to the control diet, caecal digesta $p$-cresol concentrations were significantly lower in pigs fed with AXRF (Table 3). For both diets, phenol concentration was highest in the digesta from the caecum in comparison to that from the three colon sites (Table 3). The AXRF group had lower phenol concentrations in the mid- and distal colon in comparison to the control group (Table 3). There was no effect of AXRF diet on ammonia concentrations for the caecum or any colonic sampling site (Table 3).

Mid-colon microbial profile. Microbial diversity and relative abundance were observed by hybridisation to a $16 \mathrm{~S}$ rRNA gene-based custom microarray comprised of 2240 probes representing about 700 bacterial species ${ }^{(29)}$. The hybridisation intensity of forty-five probes differed significantly $(P<0.05)$ between treatments. Overall, there was a significant difference $(P<0.05)$ in the faecal microflora
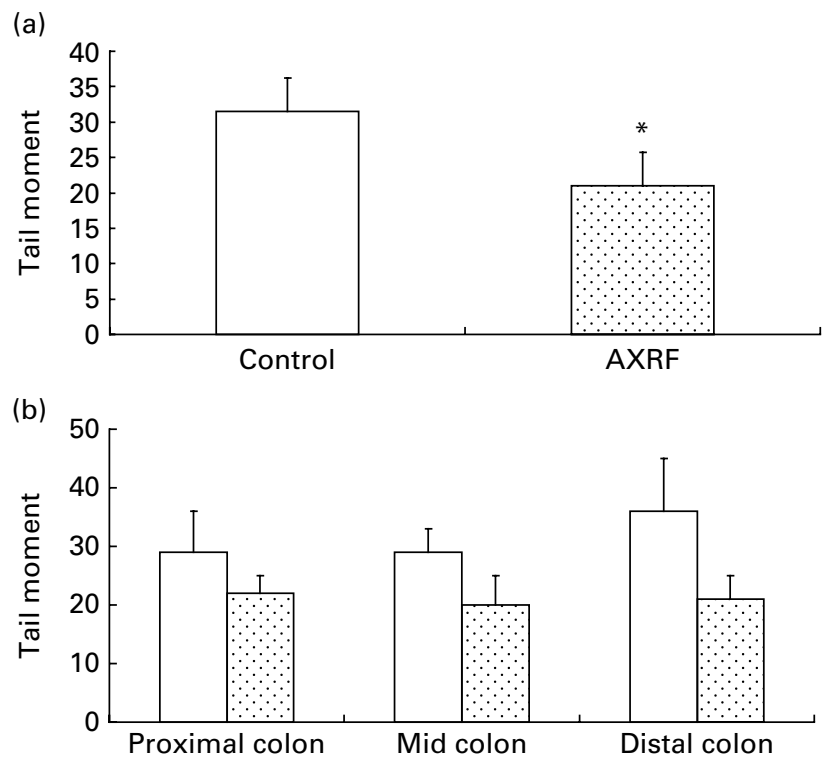

Fig. 1. Effect of (a) control ( $\square$ ) and AXRF ( $\square$ ) diets on DNA damage in colonocytes averaged from (b) the proximal, mid- and distal colon and presented for each of the three sites. DNA damage is reported as the tail moment (head density $\times$ tail length), $n 5$. ${ }^{*}$ Mean value was significantly different from that of the control group $(P<0.05)$. populations of the treatment groups, as measured by a principal component analysis of the microarray data (latter data not shown). Each individual sample based on diet, regardless of sample fractions (digesta and mucosa), exhibited distinct microbial profiles (Fig. 2). Evaluation of differences in bacterial populations based on comparative analysis of control and AXRF diet showed a significantly higher abundance of some species from the Prevotella cluster (Prevotella intermedia, $P$. disiens and $P$. ruminicola) from Bacteroidetes phylum and from Clostridial clusters IV (Faecalibacterium prausnitzii) and XIVa (Ruminococcus obeum and Blautia producta) in AXRF diet for both mucosa and digesta fractions, whereas some species of the Proteobacteria phylum (Escherichia coli and Desulfovibrio sp.), Fusobacteria, Clostridial clusters I, II and XI (C. perfringens, C. limosum and $C$. difficile, respectively), Bacteroides fragilis subgroup and $B$. distasonis were relatively higher in control pigs (Fig. 2).

Mucus thickness. The mucus thickness in the proximal, mid- and distal colon for the control diet group was 311 (sE 34), 344 ( $\mathrm{sE} 52$ ) and 349 ( $\mathrm{sE}$ 49) $\mu \mathrm{m}$, and for the AXRF diet group, it was 333 (sE 41), 299 (SE 36) and 423 (SE 41) $\mu \mathrm{m}$, respectively. There was no significant difference between dietary treatments at any of the colonic sites.

\section{Discussion}

We believe that the present study is the first to examine the effects of AXRF on large bowel SCFA and diet-induced genetic damage of colonocyte in pigs. The data are consistent with earlier reports ${ }^{(16,17,22)}$ in rodents showing that the feeding of fermentable fibre carbohydrates opposes the induction of DNA strand breaks due to higher dietary protein. On the basis of the previous studies, it might be expected that this would be related to higher large bowel SCFA concentrations and pools. Data from human surgical patients show that large bowel SCFA are highest in the proximal large bowel and are lower in the distal colon ${ }^{(32)}$. This is thought to reflect uptake on passage of the digesta coupled with the depletion of fermentative substrates. A similar distributional profile is seen in pigs and the present study confirms earlier data from rats ${ }^{(21)}$ in showing that an AXRF (similar to the one used in the present study) raised large bowel total and individual SCFA. Although in the present experiment, the concentrations of total SCFA, acetate and propionate were significantly higher, this was only in the caecum of pigs fed with AXRF. Concentrations of butyrate were unchanged in the viscus and there were no differences between any of the three major SCFA in colonic contents at any other sampling site. However, the increased caecal digesta mass in pigs fed with AXRF translated to larger pools of total and individual SCFA in that region of the large bowel. Again, these data are similar to those of Lu et al. ${ }^{(21)}$, who reported that, in rats an AXRF increased large bowel digesta and faecal mass relative to a fibre-free diet and that the increases in SCFA were as pool sizes and not concentrations. Thus, it remains possible that, if the mass of digesta was greater along the colon then the pools of SCFA (including butyrate) would also have been larger. This suggestion is supported further by the 
well-documented effects of wheat arabinoxylans in augmenting the faecal bulking effects of wheat bran ${ }^{(8)}$. The present results align with some previous animal studies that showed that fermentation of soluble NSP, including $\beta$-glucans as well as arabinoxylans, favoured propionate and acetate production over that of butyrate ${ }^{(21,33,34)}$. However, in vitro fermentation of arabinoxylans by human faecal inocula gave a SCFA profile in which butyrate was a more significant product than propionate ${ }^{(35)}$. There are data suggesting that not all arabinoxylans are equal in this regard, as the feeding of rye raises hepatic portal venous butyrate relative to wheat in pigs ${ }^{(36)}$. Some of this may reflect differences in the higher content of arabinoxylan in the former, but it may also reflect variations in the effects of the NSP content on the digestibility of starch. The inhibition of starch digestion by arabinoxylans in production animals such as chickens is well established ${ }^{(37)}$, and there are data to suggest that there may be similar effects in rats ${ }^{(38)}$. AXRF contains a proportion of starch and it might have been expected that some of this would have reached the large bowel and promoted butyrate production. Clearly, further studies are needed to determine the intrinsic effects of AXRF on large bowel fermentation and on the digestibility of other nutrients.

There are several other potential mechanisms for opposing the induction of DNA strand breaks other than through SCFA. Lowering of $\mathrm{pH}$ through direct acidification by SCFA and other acidic fermentation products is one. This is believed to inhibit the absorption of tumour promoters such as $\mathrm{NH}_{3}$, which are absorbed in the unprotonated form, i.e. at $\mathrm{pH}>7^{(39)}$. Previous studies in pigs have shown that the large bowel $\mathrm{pH}$ profile follows that of SCFA, i.e. lowest in the caecum and proximal colon and rises on passage of the digesta stream to the distal large bowel ${ }^{(40)}$. As anticipated from these data, digesta $\mathrm{pH}$ was lowest in the caecum and was significantly lower in animals fed with AXRF. Surprisingly, digesta $\mathrm{pH}$ was significantly higher in pigs fed with AXRF at all the three colonic sampling sites. The reason for this remains to be determined, but the results suggest that lowered $\mathrm{pH}$ was not involved directly in the reduction of DNA strand breaks. Potentially toxic protein degradation products such as phenols and cresols have also been implicated in increasing $\mathrm{CRC}^{(41)}$ and we have shown that their levels are increased in rats fed with a high red meat diet ${ }^{(16,17)}$. In the present study, colonic phenol concentrations were significantly lower in the midand distal colon digesta of pigs fed with AXRF, providing a possible mechanism for the lower genomic damage. A recent study in human volunteers showed that consumption of fried red meat led to greater rectal epithelial DNA damage and this was opposed by plant foods and yoghurt but, apparently, not through SCFA ${ }^{(42)}$.

It is well established that diet has a strong influence on the large bowel microbial population, and in the present study C. difficile, C. perfringens and the B. fragilis subgroup were significantly lower in the AXRF group compared with controls. These organisms can produce phenol and $p$-cresol from dietary proteins ${ }^{(43-45)}$, providing an explanation for the lower concentrations of these protein fermentation products in pigs fed with the supplemented diet (Table 3). Clostridial 


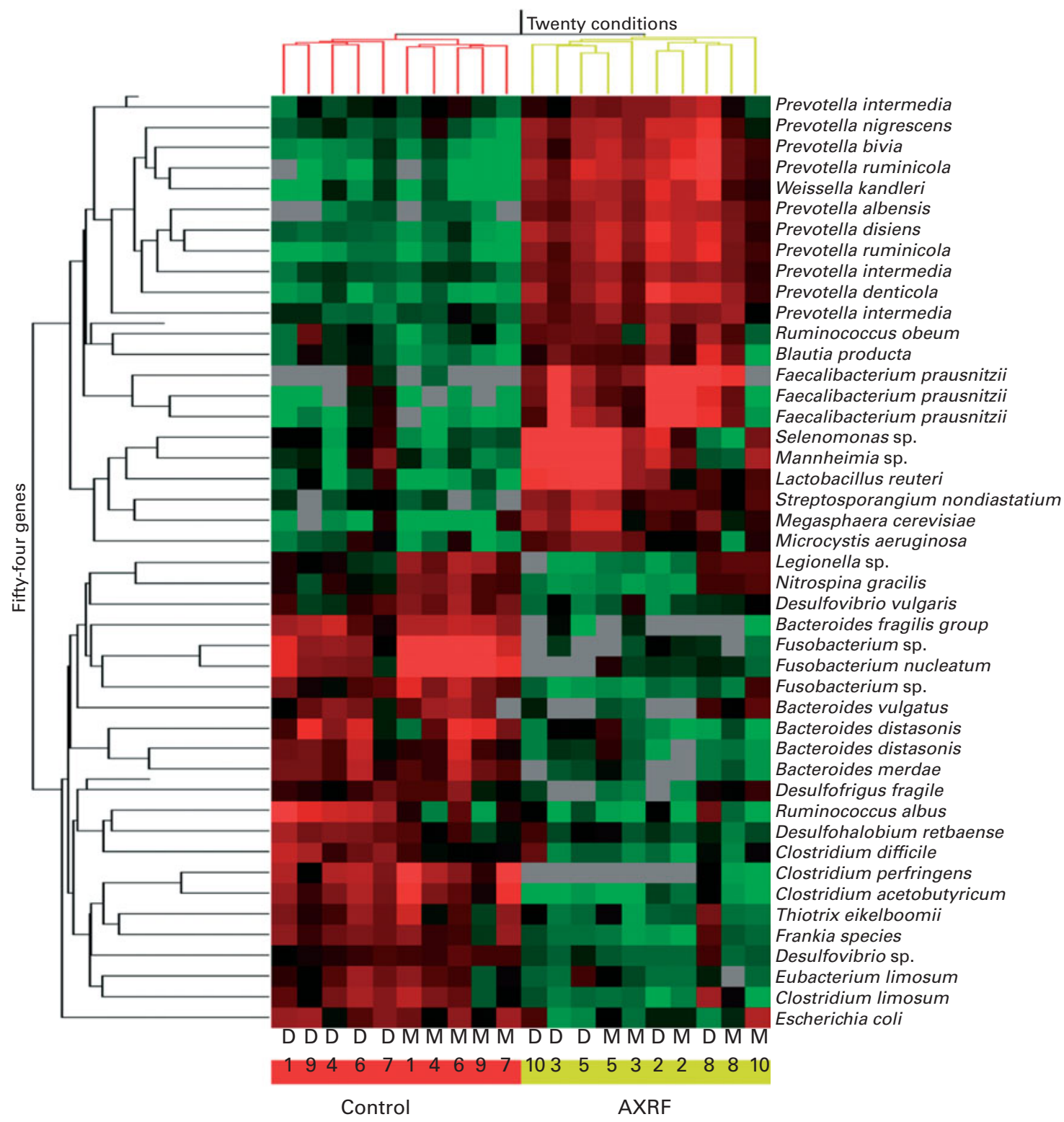

Fig. 2. Microarray heatmap analysis of microbiota in mid-colon digesta (D) and mucosa (M) from control and arabinoxylan-rich fraction (AXRF)-fed pigs. Red colour indicates high probe intensity, corresponding to an over-representation of species in the digesta sample. Conversely, green colour indicates under-representation.

clusters IV and XIVa bacteria (F. prausnitzii and B. producta, respectively) that produce butyrate as a result of carbohydrate fermentation $^{(46)}$ were also higher in response to feeding AXRF. The higher relative abundance of these butyrogenic microbial species in the AXRF diet could be of benefit in CRC or irritable bowel disease, as these bacteria are potentially protective at the gut mucosal surface ${ }^{(47)}$. Cytophaga-FlavobacteriumBacteroides phylum is a nutritionally versatile genus, and members of this genus use a diverse range of NSP as fermentable carbon source through the elaboration of a variety of hydrolytic enzymes ${ }^{(48)}$. One of the cluster, Prevotella ( $P$. intermedia, $P$. disiens and $P$. ruminicola) showed high abundance in the AXRF group. These species may have a role as particularly active organisms in arabinoxylan breakdown ${ }^{(48)}$. A recent dietary study in rats showed that an arabinoxylan preparation opposed the lowering of some bacterial species (including Bacteroides/Prevotella) induced by a high-fat diet ${ }^{(49)}$. These observations are consistent with the data obtained in the present study.

Studies in rodents have shown greater large bowel tissue mass with the feeding of fermentable fibre polysaccharides ${ }^{(50)}$. In pigs, colonic length correlates positively with the dietary content of resistant $\operatorname{starch}^{(51)}$. In the present study, the weight of caecal tissue was significantly greater in pigs fed with AXRF, whereas the colon was longer (but not significantly) in this group. It has been suggested that this could lead to colonocyte hyperproliferation and greater risk of oncogenesis $^{(52)}$. Previous findings in rats $^{(16,17,22,53)}$ as well as the present data show lower genetic damage with the feeding of polysaccharides that raise large bowel SCFA and suggest that 
this is not the case. However, there is one major difference between the present study and the study carried out in rodents. In the latter, high-protein diets led to a thinning of the large bowel mucus layer, and increasing the supply of SCFA prevented this. This may be a species difference or may also reflect the fact that the diet contained insoluble NSP (as wheat bran), and particulate matter has been shown to increase small intestinal mucus secretion in rats ${ }^{(54)}$.

The present data extend knowledge of the nutritional effects of AXRF and, taken with previous findings in rats, suggest that AXRF has beneficial effects on large intestine and factors associated with oncogenesis. Further studies to understand the mechanism of action of this fraction of wheat seem highly desirable.

\section{Acknowledgements}

The present study was funded by the 'High Fibre Grains Cluster, CSIRO Food Futures National Research Flagship', Adelaide, SA, Australia. The authors thank Jennifer Giles, Jiangqin Wei, Chia Gan, John McVeigh, Barb Gorham and Deirdre Mikkelsen for their extensive technical assistance and acknowledge Geoff Dawson and Staff from Centre for Advanced Animal Science for assistance with animals and housing. They also thank Ian Brock and Brian Burren from ARI, Yeerongpilly for conducting the SCFA and ammonia analyses and Penfords (NSW) for supply of the AXRF. D. L. T., D. P. B., A. R. B., M. A. C., M. J. G., W. L. B. and B. A. W. were involved in study design. D. P. B. and B. A. W. conducted the statistical analyses. D. L. T., D. P. B. and B. A. W. wrote the first draft of the manuscript. All authors contributed to the final version. D. L. T. had primary responsibility for final content. The authors declare no conflict of interest.

\section{References}

1. Jemal A, Murray T, Ward E, et al. (2005) Cancer statistics, 2005. CA Cancer J Clin 55, 10-30.

2. Mascie-Taylor CG \& Karim E (2003) The burden of chronic disease. Science 302, 1921-1922.

3. Norat T, Bingham S, Ferrari P, et al. (2005) Meat, fish, and colorectal cancer risk: the European Prospective Investigation into cancer and nutrition. J Natl Cancer Inst 97, 906-916.

4. Koh-Banerjee P, Franz M, Sampson L, et al. (2004) Changes in whole-grain, bran, and cereal fiber consumption in relation to $8-y$ weight gain among men. Am J Clin Nutr 80, $1237-1245$.

5. Truswell AS (2002) Cereal grains and coronary heart disease. Eur J Clin Nutr 56, 1-14.

6. Larsson SC, Rafter J, Holmberg L, et al. (2005) Red meat consumption and risk of cancers of the proximal colon, distal colon and rectum: the Swedish Mammography Cohort. Int J Cancer 113, 829-834.

7. Burkitt D (1973) Some diseases characteristic of modern Western civilization. Br Med J 1, 274-278.

8. Cummings J (1993) The effect of dietary fiber on fecal weight and composition. In CRC Handbook of Dietary Fiber in Human Nutrition, pp. 263-315 [GA Spiller, editor]. Boca Raton, FL: CRC Press.
9. Bingham SA, Day NE, Luben R, et al. (2003) Dietary fibre in food and protection against colorectal cancer in the European Prospective Investigation into Cancer and Nutrition (EPIC): an observational study. Lancet 361, 1496-1501.

10. Park Y, Hunter DJ, Spiegelman D, et al. (2005) Dietary fiber intake and risk of colorectal cancer: a pooled analysis of prospective cohort studies. JAMA 294, 2849-2857.

11. O'Keefe SJ, Kidd M, Espitalier-Noel G, et al. (1999) Rarity of colon cancer in Africans is associated with low animal product consumption, not fiber. Am J Gastroenterol 94 , 1373-1380.

12. Ahmed R, Segal I \& Hassan H (2000) Fermentation of dietary starch in humans. Am J Gastroenterol 95, 1017-1020.

13. Topping DL \& Clifton PM (2001) Short-chain fatty acids and human colonic function: roles of resistant starch and nonstarch polysaccharides. Physiol Rev 81, 1031-1064.

14. Wong JM, de Souza R, Kendall CW, et al. (2006) Colonic health: fermentation and short chain fatty acids. $J$ Clin Gastroenterol 40, 235-243.

15. Clarke JM, Topping DL, Bird AR, et al. (2008) Effects of highamylose maize starch and butyrylated high-amylose maize starch on azoxymethane-induced intestinal cancer in rats. Carcinogenesis 29, 2190-2194.

16. Toden S, Bird AR, Topping DL, et al. (2006) Resistant starch prevents colonic DNA damage induced by high dietary cooked red meat or casein in rats. Cancer Biol Ther $\mathbf{5}$, $267-272$.

17. Toden S, Bird AR, Topping DL, et al. (2007) High red meat diets induce greater numbers of colonic DNA doublestrand breaks than white meat in rats: attenuation by highamylose maize starch. Carcinogenesis 28, 2355-2362.

18. Cassidy A, Bingham SA \& Cummings JH (1994) Starch intake and colorectal cancer risk: an international comparison. $\mathrm{BrJ}$ Cancer 69, 937-942.

19. Chao A, Thun MJ, Connell CJ, et al. (2005) Meat consumption and risk of colorectal cancer. JAMA 293, 172-182.

20. Williams BA, Verstegen MW \& Tamminga S (2001) Fermentation in the large intestine of single-stomached animals and its relationship to animal health. Nutr Res Rev 14, 207-228.

21. Lu ZX, Gibson PR, Muir JG, et al. (2000) Arabinoxylan fiber from a by-product of wheat flour processing behaves physiologically like a soluble, fermentable fiber in the large bowel of rats. J Nutr 130, 1984-1990.

22. Toden S, Bird AR, Topping DL, et al. (2005) Resistant starch attenuates colonic DNA damage induced by higher dietary protein in rats. Nutr Cancer 51, 45-51.

23. Patten GS, Abeywardena MY, McMurchie EJ, et al. (2002) Dietary fish oil increases acetylcholine- and eicosanoidinduced contractility of isolated rat ileum. J Nutr 132, 2506-2513

24. King RA, May BL, Davies DA, et al. (2009) Measurement of phenol and $p$-cresol in urine and feces using vacuum microdistillation and high-performance liquid chromatography. Anal Biochem 384, 27-33.

25. Baethgen WE \& Alley MM (1989) A manual colorimetric procedure for measuring ammonium nitrogen in the soil and plant kjeldahl digests. Comm Soil Sci Plant Anal 20, 961-969.

26. McKelvey-Martin VJ, Green MH, Schmezer P, et al. (1993) The single cell gel electrophoresis assay (comet assay): a European review. Mutat Res 288, 47-63.

27. Pool-Zobel BL, Bub A, Muller H, et al. (1997) Consumption of vegetables reduces genetic damage in humans: first results of a human intervention trial with carotenoid-rich foods. Carcinogenesis 18, 1847-1850. 
28. Helma C \& Uhl M (2000) A public domain image-analysis program for the single-cell gel-electrophoresis (comet) assay. Mutat Res 466, 9-15.

29. Kang S, Denman S, Morrison M, et al. (2010) Dysbiosis of faecal microbiota in Crohn's disease patients as revealed by a custom phylogenetic microarray. Inflamm Bowel Dis 16, 2034-2042.

30. Yu Z \& Morrison M (2004) Improved extraction of PCRquality community DNA from digesta and fecal samples. Biotechniques 36, 808-812.

31. Salzman NH, de Jong H, Paterson Y, et al. (2002) Analysis of $16 \mathrm{~S}$ libraries of mouse gastrointestinal microflora reveals a large new group of mouse intestinal bacteria. Microbiology 148, 3651-3660.

32. Mitchell BL, Lawson MJ, Davies M, et al. (1985) Volatile fatty acids in the human intestine: studies in surgical patients. Nutr Res 5, 1089-1092.

33. Cheng BO, Trimble RP, Illman RJ, et al. (1987) Comparative effects of dietary wheat bran and its morphological components (aleurone and pericarp-seed coat) on volatile fatty acid concentrations in the rat. BrJ Nutr 57, 69-76.

34. Monsma DJ, Thorsen PT, Vollendorf NW, et al. (2000) In vitro fermentation of swine ileal digesta containing oat bran dietary fiber by rat cecal inocula adapted to the test fiber increases propionate production but fermentation of wheat bran ileal digesta does not produce more butyrate. $J$ Nutr 130, 585-593.

35. Pastell H, Westermann P, Meyer AS, et al. (2009) In vitro fermentation of arabinoxylan-derived carbohydrates by bifidobacteria and mixed fecal microbiota. J Agric Food Chem $\mathbf{5 7}, 8598-8606$

36. Glitso LV, Brunsgaard G, Hojsgaard S, et al. (1998) Intestinal degradation in pigs of rye dietary fibre with different structural characteristics. Br J Nutr 80, 457-468.

37. Annison G (1991) Relationship between the levels of soluble non-starch polysaccharides and the apparent metabolizable energy assayed in broiler chickens. Aust J Agric Res 38, 639-649.

38. Choct M, Illman RJ, Biebrick DA, et al. (1998) White and wholemeal flours from wheats of low and higher apparent metabolizable energy differ in their nutritional effects in rats. J Nutr 128, 234-238.

39. Visek WJ (1978) Diet and cell growth modulation by ammonia. Am J Clin Nutr 31, S216-S220.

40. Topping DL, Illman RJ, Clarke JM, et al. (1993) Dietary fat and fiber alter large bowel and portal venous volatile fatty acids and plasma cholesterol but not biliary steroids in pigs. J Nutr 123, 133-143.

41. Bone E, Tamm A \& Hill M (1976) The production of urinary phenols by gut bacteria and their possible role in the causation of large bowel cancer. Am J Clin Nutr 29, 1448-1454.

42. Shaughnessy DT, Gangarosa LM, Schliebe B, et al. (2011) Inhibition of fried meat-induced colorectal DNA damage and altered systemic genotoxicity in humans by crucifera, chlorophyllin, and yogurt. PLoS One 6, e18707.

43. Nowak A \& Libudzisz Z (2006) Influence of phenol, $p$-cresol and indole on growth and survival of intestinal lactic acid bacteria. Anaerobe 12, 80-84.

44. Sivsammye G \& Sims HV (1990) Presumptive identification of Clostridium difficile by detection of $p$-cresol in prepared peptone yeast glucose broth supplemented with $p$-hydroxyphenylacetic acid. J Clin Microbiol 28, 1851-1853.

45. Vanholder R, De Smet R \& Lesaffer G (1999) p-Cresol: a toxin revealing many neglected but relevant aspects of uraemic toxicity. Nephrol Dial Transplant 14, 2813-2815.

46. Louis P, Scott KP, Duncan SH, et al. (2007) Understanding the effects of diet on bacterial metabolism in the large intestine. J Appl Microbiol 102, 1197-1208.

47. Sokol H, Seksik P, Furet JP, et al. (2009) Low counts of Faecalibacterium prausnitzii in colitis microbiota. Inflamm Bowel Dis 15, 1183-1189.

48. Hopkins MJ, Englyst HN, Macfarlane S, et al. (2003) Degradation of cross-linked and non-cross-linked arabinoxylans by the intestinal microbiota in children. Appl Environ Microbiol 69, 6354-6360.

49. Neyrinck AM, Possemiers S, Druart C, et al. (2011) Prebiotic effects of wheat arabinoxylan related to the increase in bifidobacteria, roseburia and Bacteroides/Prevotella in diet-induced obese mice. PLoS One 6, e20944.

50. Goodlad JS \& Mathers JC (1992) Digestion of complex carbohydrates and large bowel fermentation in rats fed on raw and cooked peas (Pisum sativum). Br J Nutr 67, 475-488.

51. Topping DL, Gooden JM, Brown IL, et al. (1997) A high amylose (amylomaize) starch raises proximal large bowel starch and increases colon length in pigs. J Nutr 127, 615-622.

52. Mandir N, Englyst H \& Goodlad RA (2008) Resistant carbohydrates stimulate cell proliferation and crypt fission in wild-type mice and in the Apc(Min/+) mouse model of intestinal cancer, association with enhanced polyp development. Br J Nutr 100, 711-721.

53. Toden S, Bird AR, Topping DL, et al. (2007) Dose-dependent reduction of dietary protein-induced colonocyte DNA damage by resistant starch in rats correlates more highly with caecal butyrate than with other short chain fatty acids. Cancer Biol Ther 6, 253-258.

54. Morita T, Tanabe H, Ito H, et al. (2008) Long-term ingestion of insoluble dietary fiber increases luminal mucin content, but has no effect on nutrient absorption in rats. Biosci Biotechnol Biochem 72, 767-772. 